\title{
EFFECTS OF ARABIC GUM ON CARDIOMYOPATHY IN A RAT MODEL OF TYPE II DIABETES
}

\author{
By \\ Al-Bayomi Fouda, Adel Abd El-Aziz, and Nageh Mabrouk* \\ Departments of Medical Physiology and Pharmacology*, Al-Azhar Faculty of Medicine
}

\begin{abstract}
Background: Diabetes mellitus and the associated complications represent a global burden on human health and economics. Cardiovascular diseases are one of the leading causes of death in diabetic patients. Arabic gum (AG) is a natural compound that has a potent anti-inflammatory effect, antioxidant activity, and hypoglycemic effect.
\end{abstract}

Objective: Evaluation of the effects of Arabic gum on diabetic cardiomyopathy (DCM).

Material and Methods: Thirty-two adult male albino rats of a local strain were chosen as an animal model for this study, weighed $110-130 \mathrm{~g}$ (average weight was $120 \mathrm{~g}$ ). Diabetes mellitus type II was induced in experimental rats by using a high-fat diet (HFD) for two weeks followed by streptozotocin (STZ) injection. At the end of the experiment ( 8 weeks), serum was obtained for the determination of glucose, insulin, cardiac enzymes (lactate dehydrogenase,creatine kinase-MB fraction and AST), lipid profile (triglycerides and total cholesterol), and oxidative stress markers (Thiobarbituric acid-reactive substance and superoxide dismutase). ECG was recorded. Also, heart weight/body weight ratio (HW/BW) was calculated at the end of the experiment.

Results: Diabetic rats exhibited hyperglycemia, and hyperlipidemia accompanied by significant hypoinsulinemia. In addition, diabetic rats showed significantly increased HW/BW, serum CK-MB, AST, and lactate dehydrogenase. Oxidative stress marker increased, whereas antioxidant defenses significantly reduced in the diabetic heart. ECG also disturbed. Treatment with Arabic gum alleviated hyperglycemia, hyperlipidemia, and heart function markers. Arabic gum also minimized the oxidative stress and boosted antioxidant defenses in the heart of diabetic rats. HW/BW decreased and ECG ameliorated.

Conclusion: Arabic gum attenuated the development of DCM via amelioration of hyperglycemia/hyperlipidemia-mediated oxidative stress. Therefore, it might be worth considering the therapeutic potential of AG for human DCM.

Keywords: Hyperglycemia; Hyperlipidemia; Cardiomyopathy; Oxidative stress; Arabic gum, ECG and Diabetes mellitus.

\section{INTRODUCTION}

Cardiovascular complications due to the long-term uncontrolled hyperglycemic condition are generally considered one of the leading causes of morbidity and mortality among diabetic patients, in both developed and developing countries (Abdul-Ghaniet al., 2019). Long-standing diabetes results in structural and functional alterations in the myocardium of diabetic patients leading to diabetic cardiomyopathy. Etiology of diabetic cardiomyopathy (DCM) is very complex with several interlinked mechanisms chargeable for damage to the heart in diabetic condition. Unfortunately, exact 
molecular mechanisms and the sequence of events leading to DCM are still elusive. Oxidative stress and inflammation have been implicated to play a central role in the progression of DCM (Huynh et al., 2014). Oxidative stress, in the diabetic heart, is a major contributing factor in the development and deterioration of DCM (Li et al., 2012). Diabetic complications are generally considered to be the result of oxidative stress. In addition, diabetic complications are interrelated with the inflammatory response and have been shown to be accelerated under a hyperglycemic state for the production of acute response factors in fat cells (Wang et al., 2015). Arabic gum is non-toxic, and used extensively in pharmaceutical preparations in folk medicine, and in most categories of processed foods as in candy products. It is indigestible to both humans and animals, not degraded in the intestine, but fermented in the colon to give shortchain fatty acids, leading to a large range of possible health benefits. It has a prebiotic effect because it causes significant increases in Bifidobacteria, Lactobacteria, and Bacteroides. It has anti-carcinogenic and anti-oxidant effect with a protective role against hepatic and cardiac toxicities (Elshama et al., 2014).

The present work aimed to detect the effects of Arabic gum on diabetic cardiomyopathy in a rat model of type II diabetes.

\section{MATERIALS AND METHODS}

\section{Animals:}

Thirty-two adult male albino rats of a local strain were chosen as an animal model for this study. They kept in suitable cages $(20 \times 32 \times 20 \mathrm{~cm}$ for every four rats) at room temperature, with the natural light/dark cycle. They weighed $110-130 \mathrm{~g}$ (average weight was $120 \mathrm{~g}$ ). They were fed on a standard food in addition to bread and green vegetables with free water supply. They were kept for 10 days for the adaptation to the new environments before the start of the experiment.

\section{Chemicals:}

Streptozotocin (STZ) was purchased from Sigma-Aldrich Co., St Louis, USA. Arabic gum was obtained from the local market, Cairo, Egypt.

\section{Study design:}

Rats were divided into four equal groups:

GroupI (Normal control group): provided with standard animal pellet and water.

Group II (Arabic gum -treated normal group): Rats were offered $10 \%$ AG in drinking water for 8 weeks.

Group III (Diabetic control group).

Group IV (Arabic gum-treated diabetic group): Arabic gum was offered in $10 \%$ concentration in drinking water for 8 weeks.

\section{Induction of diabetes:}

Type II DM was experimentally induced using HFD/STZ model as described by (Skovso, 2014). Briefly, feeding with a high-fat diet (HFD) for two weeks followed by single i.p. injection of Streptozotocin (35 mg/kg body weight). Streptozotocin was dissolved in citrate buffer ( $\mathrm{pH}$ 4.5).At day 5, following STZ administration, the level of blood glucose was measured by collecting whole blood from the tail vein. Rats that had a blood glucose level of $>200 \mathrm{mg} / \mathrm{dl}$ were considered diabetic. The blood glucose level was measured using Accu-Chek glucometer (Roche, Germany). 
EFFECTS OF ARABIC GUM ON CARDIOMYOPATHY IN A RAT MODEL...

\section{Preparation of Arabic gum:}

Crude AG was obtained as spherical tears which were milled and sieved to obtain a fine pure powder. Ten grams from the powder was dissolved into 100 $\mathrm{ml}$ warm water and given to the animals orally (Abd-Allah et al., 2002). The treatments were initiated on the fifth day after STZ exposure.

\section{ECG recording:}

One day prior to euthanasia, rats were anesthetized with ketamine (100) $\mathrm{mg} / \mathrm{kg}$ i.p), and ECGs were recorded through needle electrodes inserted under the skin of the animals in lead II position using Biopac MP 35 data acquisition system (Biopac system, Canada).

\section{Biochemical parameters in blood:}

At the end of the experiment, rats were fasted for $12 \mathrm{~h}$, and samples of blood were obtained from retro-orbital venous plexus by using a heparinized capillary tube (about $0.75-1.0 \mathrm{~mm}$ internal diameter) inserted in the medial canthus. The collected blood samples were kept in centrifuge tubes until coagulated, then set centrifuged at 5000 rotations per minute for 15 minutes to separate the serum. Serum was sucked out into Eppendorf tubes and stored frozen at $-20 \mathrm{oC}$ till used for the determination of blood glucose level (Kaplan, 1984), Insulin level (Chevenne et al., 1994), cardiac enzymes (lactate dehydrogenase "LDH" - Pesce, 1984, Creatine kinase-MB fraction " $C K$ $M B$ " - Lee and Goldman, 1986) and $A$ spartate transaminase "AST"-Reitman and Frankel, 1957), Lipid profile (triglycerides "TG "- Fossati and Prencipe, 1982) and total cholesterol “TC” - Allain et al., 1974).

\section{Heart weight/body weight:}

Prior to euthanasia,the rat was weighed. After euthanasia, the heart was isolated, dried and weighed, and heart weight/body weight was calculated (Neha and Lubna, 2014).

Biochemical estimation in heart homogenate: The isolated heart tissue was homogenized in $50 \mathrm{mM}$ phosphate buffer ( $\mathrm{pH}$ 7.4) using hand-held tissue homogenizer. The resultant supernatant was used for measurement of antioxidant enzyme (SOD) and Cardiac malondialdehyde (MDA) which were measured as thiobarbituric acid reactive substances (TBARS) by the colorimetric technique (Gupta et al., 2015).

\section{Statistical analysis:}

The data were presented as mean $\pm \mathrm{SD}$. SPSS software version 25 (IBM Co., USA) was used for the statistical analysis to perform ANOVA followed by posthoc-test (LSD), where $\mathrm{P} \leq 0.05$ was considered to indicate a statistically significant difference.

\section{RESULTS}

In the DM group, STZ-induced diabetic rats exhibited a markedly higher $\mathrm{HW} / \mathrm{BW}$ ratio when compared with the control and AG-treated groups, respectively. No statistically significant difference in the HW/BW was observed between the AG-treated control group and the normal control group (Table 1).
The serum glucose and insulin level showed insignificant changes in the AGtreated control group when compared to the normal control group. In the DM group, STZ-induced diabetic rats exhibited markedly higher blood glucose and lower insulin level when compared with the control group. However, in the 
AG-treated diabetic group, the serum glucose level showed a significant decrease, while insulin level significantly increased as compared with the diabetic group (Table 1).

Table (1): Effects of treatment with Arabic gum on Blood glucose (mg/dl), insulin(? IU/ml) and $\mathrm{HW} / \mathrm{BW}(\mathrm{mg} / \mathrm{g})$ in the various experimental groups $(\mathrm{Mean} \pm \mathrm{SD})$

\begin{tabular}{|l|c|c|c|}
\hline \multicolumn{1}{|c|}{ Parameters } & $\begin{array}{c}\text { Blood } \\
\text { glucose(mg/d) }\end{array}$ & Serum insulin (?IU/ml) & HW/BW(mg/g) \\
\hline Normal Control & $89.17 \pm 3.87$ & $10.07 \pm 0.86$ & $2.61 \pm 0.3$ \\
\hline AG- treated & $87.33 \pm 2.16$ & $10.50 \pm 0.56$ & $2.77 \pm 0.3$ \\
\hline Diabetic control & $218.50 \pm 10.21^{*}$ & $7.19 \pm 0.53^{*}$ & $4.37 \pm 0.6^{*}$ \\
\hline $\begin{array}{l}\text { AG- treated } \\
\text { diabetic }\end{array}$ & $159.67 \pm 7.34^{* \dagger}$ & $8.99 \pm 0.53^{* \dagger}$ & $3.26 \pm 0.2^{* \dagger}$ \\
\hline
\end{tabular}

$\mathrm{P}^{*}$ vs. control group; $\mathrm{P} \dagger$ vs. DM group. AG, Arabic gum; HW/BW, heart weight to body weight ratio; SD, standard deviation.

The AG-treated control group revealed an insignificant change ofserum TC and TG level as compared to the normal control group.The DM group exhibited markedly higher TC and TG levels comparing the control group. However, the serum TC and TG level significantly decreased in the $A G$ treated-diabetic group as compared to the diabetic control group (Figure 1).

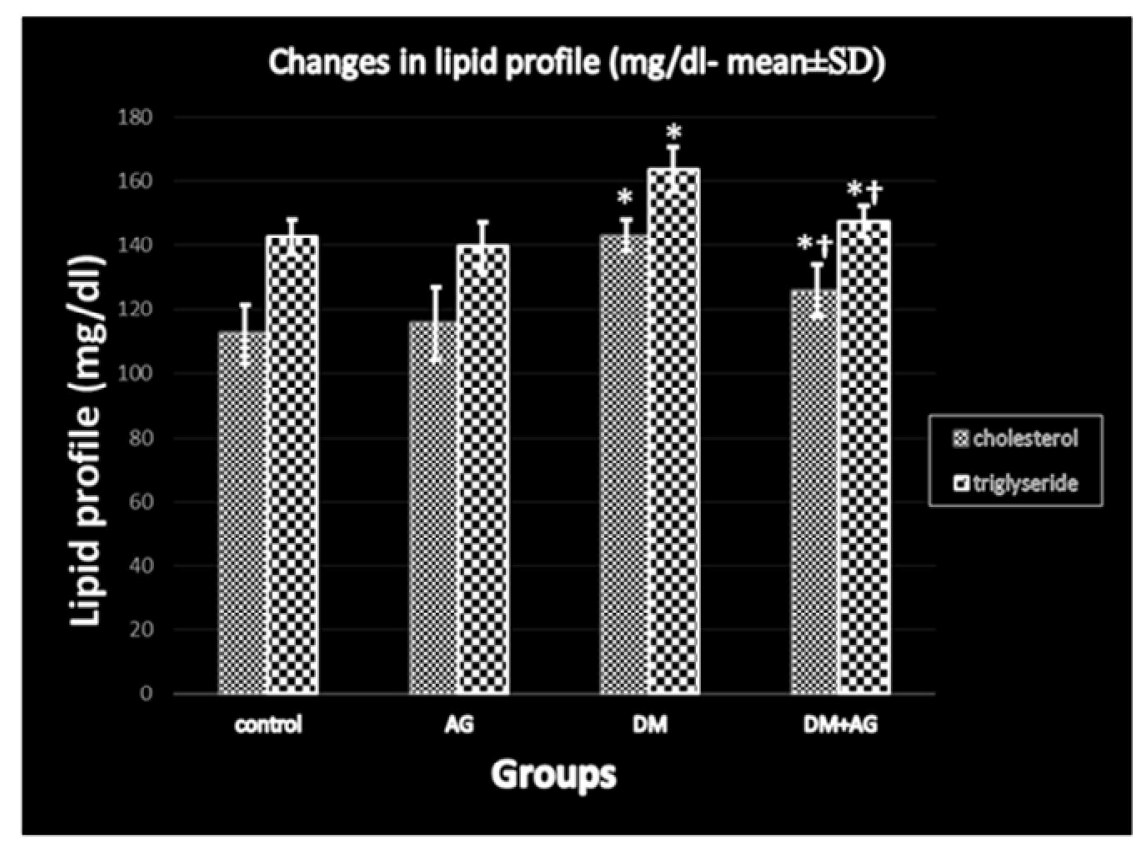

Figure (1): Effect of Arabic gum on cholesterol \& triglyceride (mean \pm SD). P* vs. control group; $\mathrm{P} \dagger$ vs. DM group ( $\mathrm{n}=8$ per group); $\mathrm{AG}$, Arabic gum; DM, diabetes mellitus. 


\section{EFFECTS OF ARABIC GUM ON CARDIOMYOPATHY IN A RAT MODEL...}

Serum CK-MB, LDH, and AST levels significantly increased in diabetic rats as compared to the control group. However, serum CK-MB, LDH and AST levels in the AG treated-diabetic group decreased significantly when compared with the diabetic control group. Normal rats treated with AG exhibited insignificant changes in cardiac enzymes as compared to control rats (Figure 2).

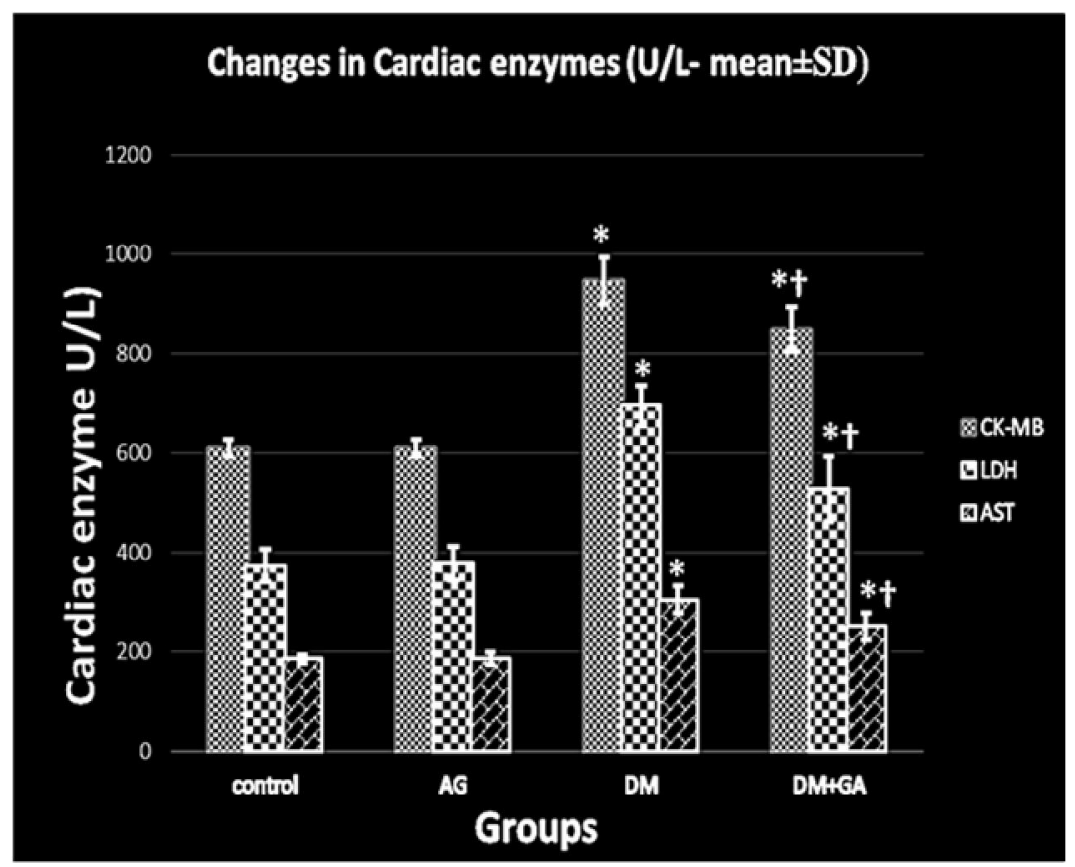

Figure (2): Effect of Arabic gum on CK-MB, LDH and AST (mean \pm SD). P* vs. control group; $\mathrm{P} \dagger$ vs. $\mathrm{DM}$ group ( $\mathrm{n}=8$ per group); $\mathrm{AG}$, Arabic gum; DM, diabetes mellitus.

ECG recordings of AG-treated control rats revealed insignificant changes in heart rate, QRS, and QT interval as compared to normal control rats. ECG of diabetic rats revealed a significantly slower heart rate and prolonged both QRS, and QT interval comparing to normal control rats. However, after adding Arabic gums to diabetic rats, heart rate, QRS, and QT interval were close to values of the normal control group (Table 2).

Table (2): Effects of treatment with Arabic gum on ECG parameters in the various experimental groups (Mean \pm SD)

\begin{tabular}{|c|c|c|c|}
\hline $\begin{array}{l}\text { Parameters } \\
\text { Groups }\end{array}$ & $\begin{array}{l}\text { Heart rate } \\
\text { (beats/min) }\end{array}$ & QRS interval (ms) & QT interval (ms) \\
\hline Normal Control & $358 \pm 6.83$ & $13.41 \pm 0.57$ & $42.49 \pm 2.24$ \\
\hline AG treated & $357 \pm 7.01$ & $13.05 \pm 0.79$ & $40.42 \pm 4.12$ \\
\hline Diabetic control & $292 \pm 7.01^{*}$ & $20.68 \pm 1.21^{*}$ & $62.57 \pm 2.84^{*}$ \\
\hline $\begin{array}{l}\text { AG- treated } \\
\text { diabetic }\end{array}$ & $317 \pm 14.74^{* \dagger}$ & $15.81 \pm 1.27^{* \dagger}$ & $55.40 \pm 3.45^{* \dagger}$ \\
\hline
\end{tabular}

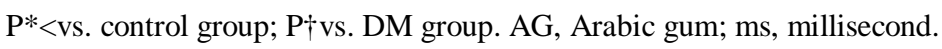


The untreated DM rats in the present study showed higher cardiac MDA and lower SOD activity. By contrast, the administration of AG to diabetic rats for 8 weeks exhibited a significant amelioration of both MDA and SOD. Normal rats treated with $A G$ showed insignificant changes in the cardiac levels of MDA and SOD as compared with control rats (Table 3).

Table (3): Effects of treatment with Arabic gum on Cardiac MDA (nmol/ $\mathrm{g}$ tissue) and SOD $(\mathrm{U} / \mathrm{g}$ tissue) in the various experimental groups $(\mathrm{Mean} \pm \mathrm{SD})$

\begin{tabular}{|c|c|c|}
\hline $\begin{array}{ll}\text { Proups } & \text { Parameters }\end{array}$ & $\begin{array}{c}\text { Cardiac MDA }(\mathrm{nmol} / \mathrm{g} \\
\text { tissue })\end{array}$ & SOD (U/g tissue) \\
\hline Normal Control & $6.4 \pm 0.4$ & $11.2 \pm 0.6$ \\
\hline AG treated & $6.1 \pm 0.2$ & $10.5 \pm 0.6$ \\
\hline Diabetic control & $15 \pm 1.2^{*}$ & $6.6 \pm 0.7^{*}$ \\
\hline AG- treated diabetic & $9.4 \pm 1.3^{*+\dagger}$ & $9.2 \pm 1.1^{*+}$ \\
\hline
\end{tabular}

P* vs. control group; $\mathrm{P} \dagger$ vs. DM group. AG, Arabic gum; MDA, malondialdehyde; SOD, Super oxide dismutase.

\section{DISCUSSION}

Diabetic cardiomyopathy is defined by the existence of abnormal myocardial structure and performance in the absence of other cardiac risk factors, such as coronary artery disease, hypertension, and significant valvular disease, in individuals with diabetes mellitus (Jia et al., 2018). Streptozotocin (STZ) type II diabetic rat model was used to investigate the protective effect of Arabic gum against diabetic cardiomyopathy. STZ induced diabetes was associated with myocardial injury in rats (Al-Rasheed et al., 2016).

In the present study, STZ diabetic rats showed a notable increase in HW/BW when compared with the control group. Diabetic rats treated with AG for 8 weeks reduced the level of HW/BW. Normal rats, received $\mathrm{AG}$ for 8 weeks, showed insignificant changes in HW/BW.Weight loss is a complication of diabetesdue to an increase ofmuscle protein catabolism, glycogenolysis lipolysis, gluconeogenesis, and polyuria which result in muscle wasting and loss of body weight (Bolla et al., 2015).
The present study was in agreement with Jia et al. (2018) who reported that hyperglycemia in diabetic patients induces cardiac hypertrophy through cardiac insulin resistance and metabolic disorders that increase mitochondria dysfunction, oxidative stress, advanced glycation end products (AGEs), impairment of mitochondria $\mathrm{Ca}^{2+} \quad$ handling, inflammation, activation of reninangiotensin-aldosterone system (RAAS), autonomic neuropathy, endoplasmic reticulum stress, cardiomyocyte death, as well as microvascular dysfunction .

Wang et al. (2014) observed that decreased heat shock protein20 $\left(\mathrm{Hsp}_{20}\right)$ in chronic diabetic hearts may be a primary factor causing the development of cardiac hypertrophy as $\mathrm{Hsp}_{20}$-mediated protection against diabetes-induced cardiac injury. Heat shock protein 20 engineered exosomes have a beneficial role in the regulation of cardiomyocyte exosome secretion and restoration of hyperglycemia-induced cardiac dysfunction (Wang et al., 2016). Also, Tan et al., (2011) found that 
EFFECTS OF ARABIC GUM ON CARDIOMYOPATHY IN A RAT MODEL...

hyperglycemia and hyperlipidemia provoke the production of proinflammatory cytokines as TNF- $\alpha$ which implicated in cardiac hypertrophy and dysfunction. In the present study, diabetic rats treated by $\mathrm{AG}$ for 8 weeks showed reduction in HW/BW, This may be due to the ability of AG to ameliorate the expression of $\mathrm{HSP}_{20}$ in cardiomyocyte in diabetic rats or due to its antiinflammatory properties which decrease TNF- $\alpha$ production.

The present study showed an insignificant change in HW/BW in healthy rats receiving $\mathrm{AG}$ for 8 weeks. A similar result was obtained by Tageldinet al., (2006) who found that weight gain significantly depressed in rabbits that consumed Arabic gum in the first week of the experiment, but weight gain was recovered thereafter. This result was in contrast with the result of (Babiker et al., 2012) who concluded that ingestion of Arabic gum caused a significant reduction in body mass index on adult females. The difference may be due to the hormonal difference as that done on female, while the present study was done on male rats.

It was evident from the results of the present work that, STZ-induced diabetic rats, exhibited significant hyperglycemia and hypoinsulinemia level than their levels in the control group. This could be due tothe selective uptake of STZ into $\beta$ cells via glucose transporter GLUT2 and destroying $\beta$-cells through damaging the nuclear DNA. Non- $\beta$ endocrine cells in pancreatic islets remain intact after STZ injection, indicating selective properties of STZ to beta cell (Goudet al., 2013). The increased blood glucose level can undergo autoxidation and no enzymatic reaction, forming a glycated product, which forms oxidants with the generation of reactive oxygen species (ROS). The increased ROS causes further damage to the $\beta$-cells because these cells have low intrinsic oxidant enzymes. Thus, the prooxidantantioxidant balance is impaired (Abdel Aziz et al., 2013).

Although the concentration levels of plasma glucose in the DM + AG group did not reduce to the same extent as that observed in the control group, the levels significantly decreased compared with the level in the DM group, while oral administration of AG for 8 weeks did not affect glucose or insulin levels in normal rats. The present study was in agreement with Pal et al., (2013) who revealed that Arabic gum exerted a significant hypoglycemic effect by initiating the release of insulin from pancreatic beta cells through removing free radicals and lipid peroxidation repression. Nasir et al., (2010) reported that AG causes down regulating of sodium glucosetransporter 1 (SGLT1), causing delay the intestinal glucose transport in diabetic mice treated with AG. On the other hand, the downregulation of SGLT1 leads to the enhancement of hunger-related hormones including leptin, cholecystokinin, and glucagon-like peptide 1 (Gorboulev et al., 2012). These hormones decrease hunger by improving post-meal satiety through many mechanisms.

The result of the current study disagreed with the result of Yasir et al., (2012) who reported that AG has a hypoglycemic effect in normal control rats. There is no conflict between the present study and that study as the study examined only the acute effect within few 
hours of administration of the $A G$ in normal control animals, and it suggested that the plant stimulates insulin secretion. This effect seemed to be counteracted by the regulatory mechanisms in case of chronic administration, which was observed in our study.

The hyperlipidemia observed in STZinduced diabetic rats could be due to oxidative stress secondary to persistent hyperglycemia (Kumar et al., 2013), or due to insulin resistance as insulin resistance correlates with hyperglycemia, and alteration in lipid metabolism (Stahlman et al., 2013).

The present study was in harmony with Almohaimeed et al., (2018) who reported that a decrease in triglyceride and cholesterol level in diabetic rats which obtained oral administration of Arabic gum.

Numerous mechanisms have been reported to explain the hypocholesterolemic effect of AG. Some studies suggested that AG increase the viscosity ofthe intestinal content and therefore, interfere with intestinal lipid absorption (Longdet et al., 2018). Another mechanism suggested that $\mathrm{AG}$ act by disrupting the enterohepatic circulation of bile acids, consequential to increased bile acid excretion, and subsequently reduces plasma cholesterol concentrations, in addition to inducing increased numbers of lipoprotein receptors in the liver and decreased plasma cholesterol concentration (Brockman et al., 2014).

The normal rats received $\mathrm{AG}$ for 8 weeks showed insignificant changes in serum lipids. This finding was supported by the results of Hegazy et al.,( 2013) who reported that $\mathrm{AG}$ did not change the lipid profile, in the normal control rats. On the other hand, these findings were contradicted with those of Yasir et al., (2012) who reported that AG has both hypoglycemic and hypolipidemic effect in normal rats as prevotellaruminicola-like bacterium was the predominant organism that is most likely responsible for fermentation of $\mathrm{AG}$ to propionate. Propionate could limit the induction of key enzymes of cholesterol metabolism hence lowers cholesterol levels. That difference may be due to the duration of administration of the AG as they administrated AG for only three weeks, while in the present study the extract of AG was administrated for 8 weeks.

Diabetes-associated cardiac injury in the current study was evidenced by the elevated circulating levels of CK-MB, $\mathrm{LDH}$, and AST. Creatin kinase-MB is a well-known sensitive marker of cardiomyocyte damage and a positive correlation between the myofibrillar disintegration and increased serum levels of CK-MB has been reported (Upaganlawar and Balaraman, 2010). In support of these findings, Al-Rasheed et al., (2016) demonstrated that serum CKMB and AST elevated in experimentalinduced DCM in rats. Interestingly, treatment with AG significantly ameliorated the circulating $\mathrm{CK}-\mathrm{MB}, \mathrm{LDH}$ and AST levels, and prevented hyperglycemia-induced cardiomyocyte injury, demonstrating its cardioprotective efficacy. The present study was in line with Nemmar et al., (2019) who reported that Arabic gum ameliorates cardiotoxicity induced by water- pipe smoke exposure in mice by a mechanism which involves activation of the Nrf2 (nuclear factor-like 2) signaling 
EFFECTS OF ARABIC GUM ON CARDIOMYOPATHY IN A RAT MODEL...

pathway. $\mathrm{Nrf}_{2}$ is a critical transcription factor which plays a major role in activating antioxidant enzymes to respond to oxidative stress (Barancik et al., 2016).

Regarding electrocardiographic (ECG) parameters, HR, QRS duration and QT interval are valid predictors of heart disease and fatal ventricular arrhythmia. The prevalence of a prolonged QT interval is higher in people with diabetes as compared to non-diabetic individuals. Moreover, QRS duration and R-wave amplitude (RWA) are early indicators of evolving cardiovascular disease and increased cardiovascular risk (Nakos et al., 2018).

In the present study, the STZ induced diabetic rats showed a decrease in HR than control rats. This result was in agreement with Mostarda et al., (2013) who found that streptozotocin-induced diabetes produces bradycardia through autonomic neural dysfunction and sinoatrial node impairment.

Various studies proved the beneficial role of bioflavonoid in improving cardiac function/ electrophysiology in diabetic animals (Annapurna et al., 2009). In the present study, AG improves cardiac function in diabetic rats by normalizing cardiac electrophysiology as it contains bioflavonoid.

The untreated DM rats in the present study showed a significant increase in the cardiac MDA, and the activity of SOD significantly diminished. By contrast, the administration of $A G$ to diabetic rats for 8 weeks exhibited a significant amelioration of both MDA and SOD. Normal rats treated with AG showed insignificant changes in the cardiac levels of MDA and SOD.
In the present study, STZ-induced diabetic rats showed reductions in activities of SOD with increments in MDA that could reflect oxidative pressure. This might be a mirror to diminished antioxidant defense potentialas hyperglycemia and hyperlipidemias are associated with increased production of ROS (Tiwari et al., 2013). Arabic gum ameliorated both MDA and SOD due to its containing four antioxidant minerals, i.e. copper, iron, manganese, and zinc, or due to its positive effect on the expression of the antioxidant enzymes (Kong et al., 2014), or due to the ability of AG to reduce the expression of HSP70 mRNA in the heart of diabetic rat. Heat-shock protein 70 (HSP70), a stress-induced protein is proposed to play a protective role against oxidative stress (Ahmed et al., 2015). Ali, (2004) reported that Arabic gum did not significantly affect lipid peroxidation (LP), and superoxide dismutase (SOD) in the kidneys and liver of healthy rats.

\section{CONCLUSION}

AG attenuated cardiomyopathy via amelioration of hyperglycemia and attenuation of oxidative stress, inflammation, and consequent apoptotic cell death. Thus, AG possesses a therapeutic potential for the treatment and/or prevention of DCM.

\section{REFERENCES}

1. Abd-Allah, A.R., Al-Majed, A.A., Mostafa, A.M., Al-Shabanah, O.A., Gamal El-Din, A. and Nagi, M.N. (2002): Protective effect of Arabic gum against cardiotoxicity induced by doxorubicin in mice: a possible mechanism of protection. J Biochem Mol Toxicol., 16(5):254 259. 


\section{AL-BAYOMI FOUDA et al.,}

2. Abdel Aziz, M.T., El-Asmar, M.F., Rezq, A.M., Mahfouz, S.M., Wassef, M.A.andFouad, H.H. (2013): The effect of a novel curcumin derivative on pancreatic islet regeneration in experimental type-I diabetes in rats (long term study). Diabetol Metab Syndr., 5-75.

3. Abdul-Ghani, M. A., Jayyousi, A., DeFronzo, R. A., Asaad, N. and Al-Suwaidi, J. (2019): Insulin resistance the link between T2DM and CVD: basic mechanisms and clinical implications. Curr Vasc Pharmacol., 17 (2):153-163.

4. Ahmed, A.A., Fedail, J.S., Musa, H.H., Ali, A., Kambohe, Amal Z. Sifaldin, A. and Musa, T.H. (2015): Arabic gum extracts protect against hepatic oxidative stress in alloxan-induced diabetes in rats. Pathophysiology, 22: 189-194.

5. Ali, B.H. (2004): Does Arabic gum have an antioxidant action in rat kidney? A preliminary study. Ren Fail., 26(1):1-3.

6. Allain, C., Poon, L., Chan, C., Richmond, W. and Fupc, C. (1974): Enzymatic determination of total serum cholesterol. Clinical Chemistry Journal, 20: 470- 475.

7. Almohaimeed, H.M., Amin, H.A., Abd ElAziz, G.S. and Saleh, H. A. (2018): Arabic gum acacia improves diabetic peripheral neuropathy in rats: a biochemical and histopathological evidence.International Journal of Basic \& Clinical Pharmacology, 7(6):10651071.

8. Al-Rasheed, N.M., Al-Rasheed, N.M., Hasan, I.H., Al-Amin, M.A., Al-Ajmi, H.N.and Mahmoud, A.M. (2016): Sitagliptin attenuates cardiomyopathy by modulating the JAK/STAT signaling pathway in experimental diabetic rats. Drug Des Devel Ther., 10: 2095-2107.

9. Annapurna, A., Reddy, C.S., Akondi, R.B. and Rao, S.R.C. (2009): Cardioprotective actions of two bioflavonoids, quercetin, and rutin, in experimental myocardial infarction in both normal and streptozotocin-induced type I diabetic rats. J. Pharm. Pharmacol., 61:13651374.

10. Babiker, R. Merghani, T.H. Elmusharaf, K. Badi, R.M. Lang, FandSaeed, A.M. (2012):
Effectsof Arabic gum ingestion on body mass index and body fat percentage inhealthy adult females: two-arm randomized, placebocontrolled, double-blind trial, Nutr J., 11: 111119.

11. Barancik, M., Gresova, L., Bartekova, M. and Dovinova, I. (2016): Nrf2 as a key player of redox regulation in cardiovascular diseases.Physiol. Res., 65(1):1-10.

12. Bolla, K.,Sri, K.V. andVaralakshmi,K. (2015): Diabetes mellitus and its prevention. IntJ ScienTech Res.,4(8):119-125.

13. Brockman, D.A., Chen, X. and Gallaher, D.D. (2014): High-viscosity dietary fibers reduce adiposity and decrease hepatic steatosis in rats fed a high-fat diet. J Nutr., 144:14151422.

14. Chevenne, D., Ruiz, J., Lohmann, L., Laudat, A., Leblanc, H. and Gray, I.P. (1994): Immuno radiometric assay of human intact proinsulin applied to patients with type II diabetes, impaired glucose tolerance, and hyperandrogenism.ClinChem., 40:754-757.

15. Elshama, S., El-Kenawy, A., Osman, H. and Youseef, H. (2014): Amelioration of indomethacin systemic toxicity by Arabic gum administration in adult albino rats. Int. J. Med. Plant Altern Med., 2(3): 32-46.

16. Fossati, P. and Prencipe, L. (1982): Serum triglycerides determined colorimetrically with an enzyme that produces hydrogen peroxide. Clinical Chemistry Journal, 28(10): 2077-2080.

17. Gorboulev, V., Schürmann, A., Vallon, V., Kipp, H., Jaschke, A. and Klessen, D. (2012): Na-glucose cotransporter SGLT1 is pivotal for intestinal glucose absorption and glucosedependent incretin secretion. Diabetes, 61(1):187-196.

18. Goud, B., Dwarakanath, V. andChikka, B. (2013): Streptozotocin a diabetogenic agent in animal models.IJPPR,3(1):254-269.

19. Gupta, S.K., Dongare, S. and Mathur, R. (2015): Genistein ameliorates cardiac inflammation and oxidative stress in streptozotocin-induced diabetic cardiomyopathy in rats. Mol. Cell Biochem.,408:63-72. 
EFFECTS OF ARABIC GUM ON CARDIOMYOPATHY IN A RAT MODEL...

20. Hegazy, G.A., Alnoury, A.M.and Gad, H.G. (2013): The role of Acacia Arabica extract as an antidiabetic, antihyperlipidemic, and antioxidant in streptozotocin-induced diabetic rats. Saudi Medical Journal, 34(7):727-733.

21. Huynh, K., Bernardo, B.C., McMullen, J.R. and Ritchie, R.H. (2014): Diabetic cardiomyopathy: mechanisms and new treatment strategies targeting antioxidant signaling pathways. Pharmacol Ther., 142:375415.

22. Jia, G., Hill, M. and Sowers, J. (2018): Diabetic cardiomyopathy: an update of mechanisms contributing to this clinical entity.Circ Res., 122(4): 624-638.

23. Kaplan, A. (1984): Glucose. Journal of Clinical Chemistry, 1032 -1036.

24. Kong, H., Yang, J., Zhang, Y., Fang, Y. and Nishinari, K. (2014): Synthesis and antioxidant properties of Arabic gum -stabilized selenium nanoparticles. IntJ.BiolMacromol., 65: 155-162.

25. Kumar, V., Ahmed, D., Gupta, P.S., Anwar, F.and Mujeeb, M. (2013): Anti-diabetic, antioxidant and anti-hyperlipidemic activities of Melastomamalabathricum Linn. Leaves in streptozotocin-induced diabetic rats. BMC Complement Altern Med., 13(222):1-19.

26. Lee, T.H. and Goldman, L. (1986): Serum enzyme assays in the diagnosis of acute myocardial infarction. Ann Intern. Med., 105: 221-233.

27. Li, C.J., Lv, L., Li, H. and Yu, D.M. (2012): Cardiac fibrosis and dysfunctionin experimental diabetic cardiomyopathy are amelioratedby alpha-lipoic acid. CardiovascDiabetol., 11-73.

28. Longdet, I. Y., Eyibo, A. S., Istifanus, G., Blessing, O. E., Bogolnaan, A. D. and Denkok, Y. (2018): Determination of the effect of gum Arabic on body weight and some biochemical parameters on albino wistar ratEJNFS., 8(1):15-19.

29. Mostarda, C., Rocha, L., and Barboza C. (2013): Ventricular and autonomic benefits of exercise training persist after detraining in infarcted rats. Eur J App Physio, 113(5):11371146.
30. Nakos, I., Kadoglou, N., Gkeka, P., Tzallas, A., Giannakeas, N., Tsalikakis, D., Katsimpoulas, M., Mantziaras, G., Kostomitsopoulos, N., Liapis, C.andKakisis, J. (2018): Exercise training attenuates the development of cardiac autonomic dysfunction in diabetic rats.In Vivo, 32(6): 1433-1441.

31. Nasir, O., Artunc, F., Wang, K., Rexhepaj, R., F?ller, M. and Ebrahim, A. (2010): Down-regulation of mouse intestinal Nacoupled glucose transporter SGLT1 by Arabic gum (Acacia Senegal). Cell Physiol Biochem., 25(23):203-210.

32. Neha, K. and Lubna, A. (2014): Evaluation of the cardioprotective effect of tinosporacordifolia against isoprenalineinduced myocardial infarction in rats. Int. J. Curr. Microbiol. App Sci., 3(3): 543-555.

33. Nemmar, A., Al-Salam, S., Beegam, S., Yuvaraju, P. and Ali, B. H. (2019): Gum Arabic ameliorates impaired coagulation and cardiotoxicity induced by water-pipe smoke exposure in mice.Front Physio., 10(53):1-12.

34. Pal, R., Hooda, M., Bhandari, A. and Singh J. (2013): Antidiabetic activity of Acacia Senegal Pod extract in streptozotocin-induced diabetic rats. International Journal of Indigenous Medicinal Plants, 46: 1400-1404.

35. Pesce, A. (1984): Lactate dehydrogenase. Kaplan A. Clin. Chem., 438: 1117-1124.

36. Reitman, S. and Frankel, S. (1957): A calorimetric method for the determination of serum glutamic oxalo acetic and glutamic pyruvic transaminase. Am. J. Clin. Path., 20: 28-56.

37. Skovso, S. (2014): Modeling type 2 diabetes in rats using high-fat diet and streptozotocin. J Diabetes Invest., 5: 349-358.

38. Stahlman, M., Fagerberg, B., Adiels, M., Ekroos, K., Chapman, J.M.andKontush, A. (2013): Dyslipidemia, but not hyperglycemia and insulin resistance, is associated with marked alterations in the HDL lipidome in type 2 diabetic subjects in the DIWA cohort: impact on small HDL particles. Biochim Biophys Acta, 1831:1609-1617.

39. Tageldin, S., Elkhalifa, K.F. and Abbas,K. (2006): The effect of gum Arabic on body 
weight and somebody elements in NewZealand cross California and Baladi rabbits. Pakistan Journal of Biological Sciences, 9(1):96-98.

40. Tan, Y. Ichikawa, T. Li, Q. J. Si, H. Yang, X. Chen, C.S. Goldblatt, C.J. Meyer, X. Li, Land Cai, T. (2011): Diabetic down-regulation of Nrf2 activity via ERK contributes to oxidative stress-induced insulin resistance in cardiac cells in vitro and in vivo. Diabetes, 60: 625-633.

41. Tiwari, B.K., Pandey, K.B., Abidi, and A.B.and Rizvi, S.I. (2013): Markers of oxidative stress during diabetes mellitus. J Biomarkers, 1-8.

42. Upaganlawar, A and Balaraman, R. (2010): Protective effects of lagenariasiceraria (Molina) fruit juice in isoproterenol-induced myocardial infarction, Int J Pharm., 6: 645-651.

43. Wang, X., Gu, H., Huang, W., Peng, J., Li, Y., Yang, L., Qin, D., Essandoh, K., Wang, Y., Peng, T.and Fan, G.C. (2016): Hsp20mediated activation of exosome biogenesis in cardiomyocytes improves cardiac function and angiogenesis in diabetic mice. Diabetes, 65:3111-3128.
44. Wang, X., Huang, W., Liu, G., Cai, W., Millard, R.W., Wang, Y., Chang, J., Peng, T. and Fan, G.C. (2014): Cardiomyocytes mediate anti-angiogenesis in type 2 diabetic rats through the exosomal transfer of miR-320 into endothelial cells. J Mol Cell Cardiol., 74:139150.

45. Wang, Y., Ming Ge, Z., QiangKang,W., XunLian,Z. and Yong Zhou,C. (2015): Rutin alleviates diabetic cardiomyopathy in a rat model of type 2 diabetes. Experimental and Therapeutic Medicine, 9: 451-455.

46. Yasir, M., Shrivastava, R., Jain, P., Das, D., Yasir, M. and Shrivastava, R. (2012): Hypoglycemic and anti-hyperglycemic effects of different extracts and combinations of with acacia Arabica lamk in normal and alloxan induced diabetic rats. Pharmacognosy Communications, 2: 61-66. 


\title{
EFFECTS OF ARABIC GUM ON CARDIOMYOPATHY IN A RAT MODEL...
}

\section{تثأثيرات الصمغ العربي على إعتلال عضلة القلب للدى الجرذان المصابة بالنوع الثاذي من داء السكرى}

\author{
* البيومى فوده- عادل عبدالعزيز - ناجح مبروك \\ قسمى الفسيولوجيا الطبية والفارماكولوجى* ـ كلية طب الأزهر
}

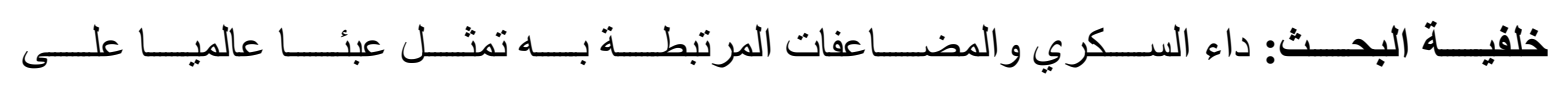

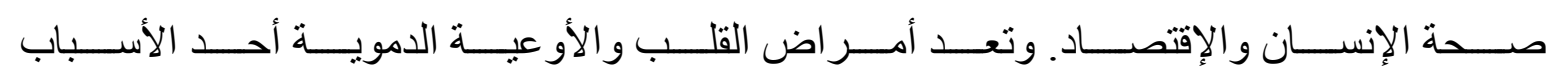

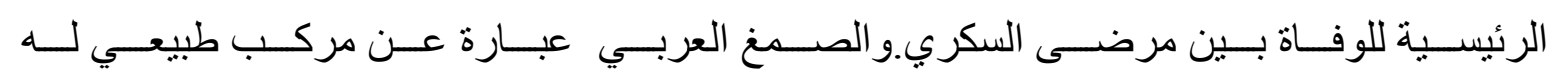

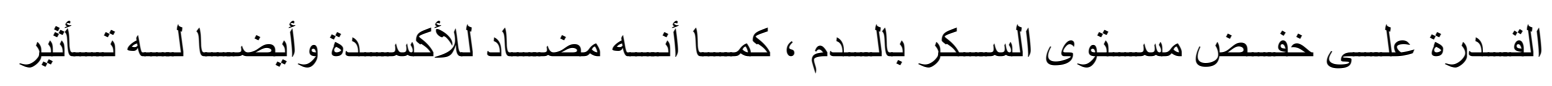
فعال مضناد للإلتهابات.

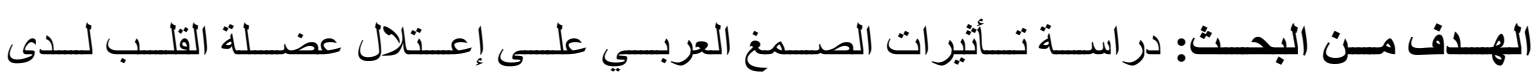
الجرذان المصابة بالنوع الثاني من داء السكرى.

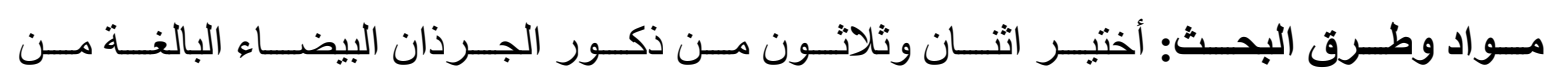

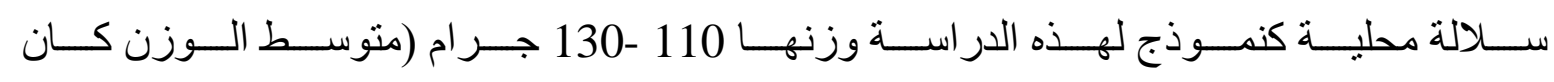

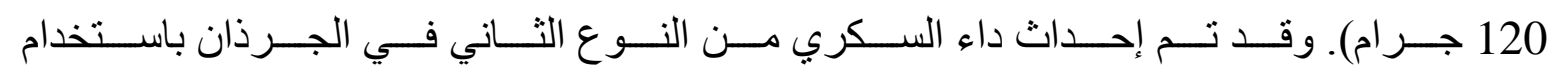

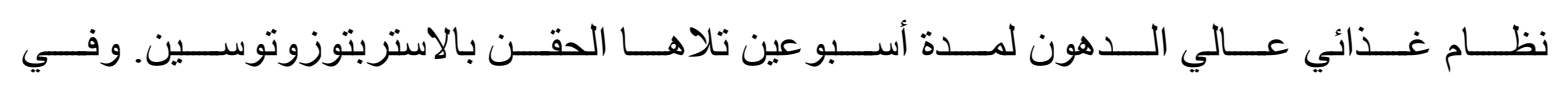

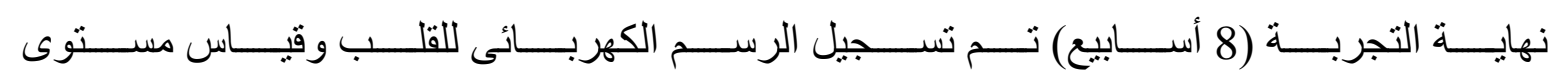

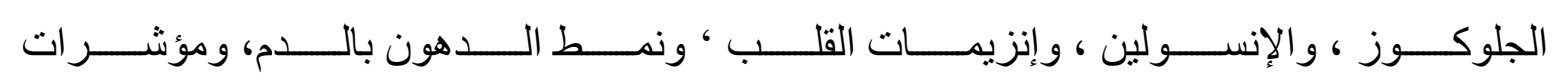
الأكسدة بالقلب. كما تم حساب نسبة وزن القلب / وزن الجسم.

التتــائج: أســفرت نتــائج الجــرذان المصـــابة بـــداء الســكري عــن تغيــر ات فــى الرســـم

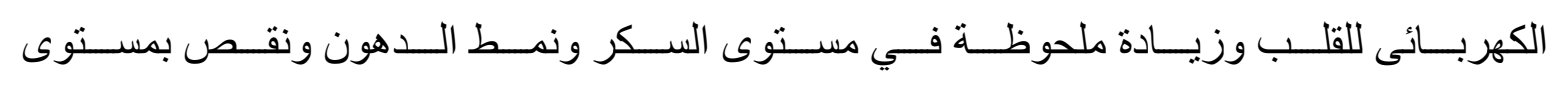

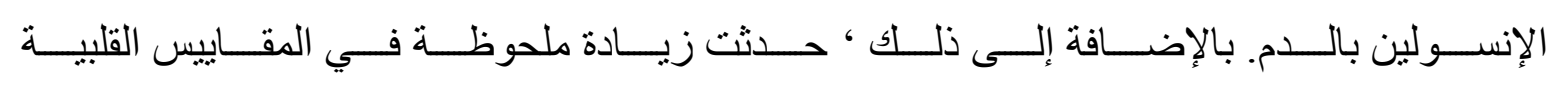

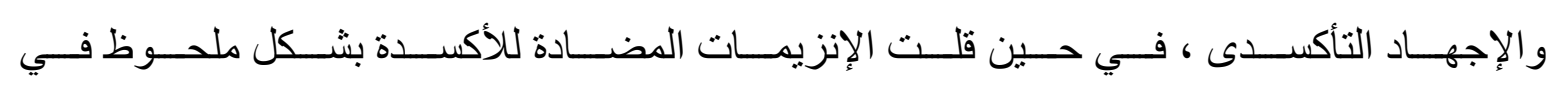

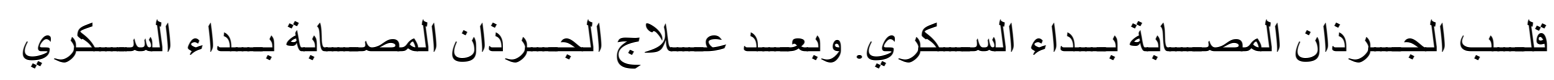

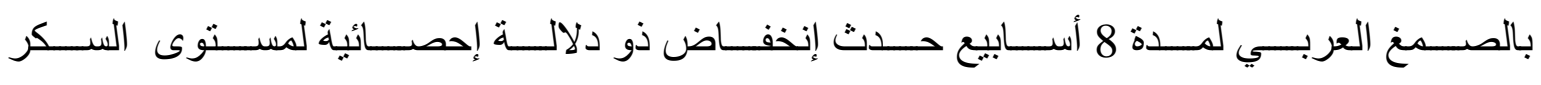

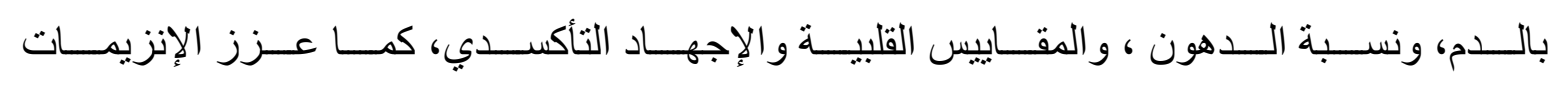




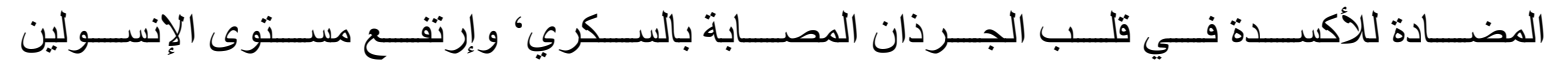
بالدم، وتحسن الرسم الكهربائي للقلب.

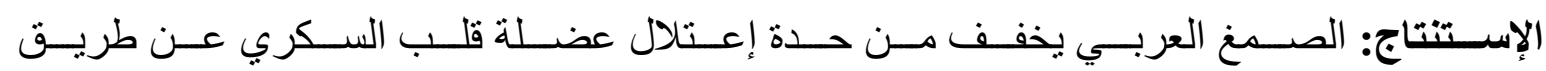

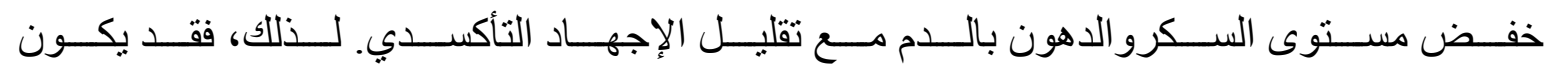

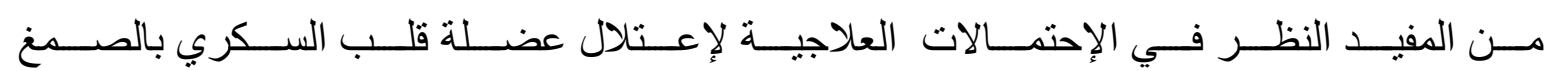
العربى. 